Article

\title{
Biosynthesis of Copper Oxide (CuO) Nanowires and Their Use for the Electrochemical Sensing of Dopamine
}

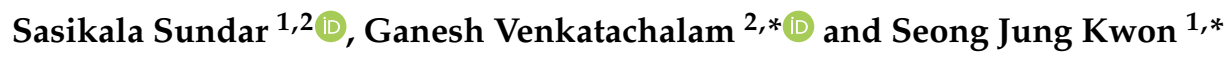 \\ 1 Department of Chemistry, Konkuk University, 120 Neungdong-ro, Gwangjin-gu, Seoul 143-701, Korea; \\ sasikala412@gmail.com \\ 2 Electrodics and Electrocatalysis (EEC) Division, CSIR-Central Electrochemical Research \\ Institute (CSIR-CECRI), Karaikudi 630003, Tamilnadu, India \\ * Correspondences: vganesh@cecri.res.in (G.V.); sjkwon@konkuk.ac.kr (S.J.K.)
}

Received: 17 September 2018; Accepted: 9 October 2018; Published: 12 October 2018

\begin{abstract}
A facile one-step, eco-friendly, and cost-effective approach for the formation of copper oxide $(\mathrm{CuO})$ nanowires by a green method using saponin-rich Sapindus mukorossi fruit extract (SMFE). The physio-chemical characteristics of the synthesized $\mathrm{CuO}$ nanowires have been characterized by X-ray Diffractometry (XRD), X-ray Photoelectron Spectroscopy (XPS), FT-IR (Fourier Transform Infrared Spectroscopy, FE-SEM (Scanning Electron Microscopy), and High-Resolution Transmission Electron Microscopy (HR-TEM). Further, the electrocatalytic activity of the $\mathrm{CuO}$ nanowires synthesized with SMFE has been investigated, and they have been used as dopamine (DA) sensors. Because of their unique properties, the $\mathrm{CuO}$ nanowires/GCE exhibited remarkable electrochemical response for the detection of DA with enhanced current response. The anodic current demonstrated that the $\mathrm{CuO}$ nanowires/GCE linearly detects the concentration of DA over the range of $0.1 \mu \mathrm{M}$ to $0.105 \mathrm{mM}$ of DA with a regression co-efficient of 0.9960 . The obtained results illustrated that the synthesized $\mathrm{CuO}$ nanowires can easily stimulate the electron transfer reaction between DA and the nanowires modified electrode with the improvement of the conductivity and stability of the electrode. This remarkable electrocatalytic property of $\mathrm{CuO}$ nanowires makes it a unique electrochemical sensor for the detection of DA. Furthermore, the sensor is free from the interference of ascorbic acid, uric acid, and other interfering species. Moreover, the anti-interference performance also showed that the $\mathrm{CuO}$ nanowires/GCE could be employed for the determination of DA in real samples with good selectivity and sensitivity.
\end{abstract}

Keywords: biosynthesis; copper oxide; nanowires; dopamine; electrochemical biosensor

\section{Introduction}

Owing to the attractive physicochemical properties of transition metal or metal oxide nanostructured materials, significant attempts have been promoted towards the preparation of such metal/metal oxide nanoparticles with desired shapes and sizes [1,2]. Among the transition metal oxides, $\mathrm{CuO}$ is one of the best known naturally occurring $p$-type semiconductors, and in particular, nanostructured copper oxides are especially versatile and they offer unique characteristics in many applications in sensors, high-critical-temperature superconductors, lithium-ion batteries, field emission emitters, and catalysts [3-7]. The size and morphology of the $\mathrm{CuO}$ nanostructured materials considerably affect their electrochemical activity [8]; therefore, controlling the morphology and the enhancement of the cyclability of $\mathrm{CuO}$-based electrodes are crucial. In order to improve these novel properties, synthesis of $\mathrm{CuO}$ nanostructures in the form of nanowires, nanorods, nanoneedles, 
nanoflowers, and nanoparticles, which show excellent electrochemical performance as compared to their bulk counterparts. Over the past few years, variety of preparation methods have been developed to generate $\mathrm{CuO}$ nanoparticles with varying dimensions and structures such as the self-catalytic mechanism, simple solution preparation, hydrolysis, hydrothermal and solvothermal synthesis, and exposure to microwave irradiation [9-14]. However, these chemical methods involve the use of toxic, very expensive, hazardous, and non-environmentally friendly chemicals, thus they are not acceptable for the various fields of biomedical applications. Hence, the influence of green synthesis provides advancement over chemical and physical method, as it is cost effective, eco-friendly, easily scaled up for large scale synthesis, and provides no need to use high pressure, energy, temperature, and toxic chemicals for the synthesis of morphology controlled nanostructured materials, which will find extensive use in biomedicine [15].

Several types of neurotransmitter related diseases, such as Parkinson's and Alzheimer's diseases, epilepsy and schizophrenia, can be caused by the abnormal metabolism and concentration of Dopamine (4-(2-aminoethyl)benzene-1,2-diol) [16]. For this reason, and because of its important role in physiology and pathophysiology, it is necessary to explore a cost effective, sensitive and reliable quantitative method for the determination of dopamine (DA) in the biological fluids. Compared with traditional analytical methods, electroanalytical methods are highly sensitive and selective, rapid and inexpensive [17]. When compared to the metal electrodes, nanostructured metal oxide fabricated electrode materials provide some unique electrochemical characteristics and induces higher reaction rates with the exclusion of weakly adsorbed hydrogen species being present on the surface of the oxides [18]. Various types of nanostructured metal oxides, like $\mathrm{ZnO}$ nanowires, $\mathrm{RGO}-\mathrm{TiO}_{2}$ nanocomposites, $\mathrm{RuO}_{2} / \mathrm{CNT}, \mathrm{Fe}_{3} \mathrm{O}_{4}$ nanorods/grapheme, $\mathrm{Fe}_{3} \mathrm{O}_{4} @ \mathrm{Au}$ nanoparticles, graphene $/ \mathrm{SnO}_{2}$, and $\mathrm{WO}_{3}$ nanoparticles, have been efficiently developed for the determination of DA in the biological samples [19-25]. Among these electrocatalysts, distinctive properties of copper oxide $(\mathrm{CuO})$ have achieved higher interest, especially in the fields of electrochemical biosensors [26-30]. Based on the previous investigations and experience on the synthesis of different phases of magnetic (iron oxides) metal oxides, such as $\mathrm{Fe}_{3} \mathrm{O}_{4}, \gamma-\mathrm{Fe}_{2} \mathrm{O}_{3}$, and $\alpha-\mathrm{Fe}_{2} \mathrm{O}_{3}$ using Sapindus mukorossi fruit extract (SMFE) [31] for the development of electrochemical biosensors, we have examined here the electrocatalytic behavior of one-dimensional copper oxide nanowires modified GCE synthesized using SMFE for the sensitive and selective determination of DA.

\section{Materials and Methods}

\subsection{Materials}

Copper (II) sulfate hexahydrate $\left(\mathrm{CuSO}_{4} \cdot 6 \mathrm{H}_{2} \mathrm{O}\right)$, sodium hydroxide $(\mathrm{NaOH})$ were purchased from Merck (Mumbai, India). Sapindus mukorossi fruits were obtained from the local market (Tamil Nadu, India). Uric acid (UA), ascorbic acid (AA), citric acid (CA), dopamine (DA), glucose, sodium chloride $(\mathrm{NaCl})$, dihydrogen orthophosphate and dipotassium hydrogen phosphate were obtained from Sigma-Aldrich (St. Louis, MO, USA). All of the above purchased chemicals were used without any additional purification process. Ultrapure water $(>18 \mathrm{M} \Omega$, Millipore, Darmstadt, Germany) was used in all the experiments.

\subsection{Preparation of Sapindus Mukorossi Fruit Extract (SMFE)}

About $10 \mathrm{~g}$ of the dried fruits were dissolved in conical flask containing $100 \mathrm{~mL}$ water and stirred for $12 \mathrm{~h}$. The brownish yellow colored extracted solution was filtered through Whatman No. 1 filter paper. Finally, the collected filtrate was kept at $4{ }^{\circ} \mathrm{C}$ and was used for the further experimental process.

\subsection{Preparation of $\mathrm{C} u O$ Nanowires Using SMFE}

Typically, $\mathrm{CuO}$ nanowires were prepared by a simple precipitation process that was based on a modified version of the procedure reported in the literature [31]. A stoichiometric amount of $0.1 \mathrm{M}$ $\mathrm{CuSO}_{4} \cdot 6 \mathrm{H}_{2} \mathrm{O}$ was mixed with $2 \mathrm{~mL}$ of SMFE and stirred well for $10 \mathrm{~min}$. An aqueous solution of 
$0.1 \mathrm{M} \mathrm{NaOH}$ was introduced slowly into the above mixture until it reaches $\mathrm{pH} 11$ and allowed to stir for $2 \mathrm{~h}$ at ambient atmosphere. The obtained bluish green precipitate indicates the formation of Copper (II) hydroxide, and then the resultant precipitate was centrifuged and washed for 2-3 times using de-ionized water. Finally, the decanted precipitate was dried in an oven for $24 \mathrm{~h}$ at $80{ }^{\circ} \mathrm{C}$ and placed in a preheated furnace at $300{ }^{\circ} \mathrm{C}$ for $1 \mathrm{~h}$ to get the $\mathrm{CuO}$ nanostructures. The above-mentioned synthesis method was performed in the greener environment without the presence of any inert gases or a vacuum atmosphere.

\subsection{Characterizations of $\mathrm{CuO}$ Nanowires}

The green synthesized copper oxide nanowires were characterized by various physiochemical techniques. X-ray diffractometry (XRD) was recorded to identify the crystal structure with $\mathrm{CuK} \alpha$ radiation (PANalytical X'Pert Pro Diffractometer, Almelo, The Netherlands). X-ray Photoelectron Spectrometer (XPS) of the $\mathrm{CuO}$ nanowires was used to confirm the chemical compositions and the oxidation states of the formed products by Kratos ASIS-HS, X-ray photoelectron spectrometer (Thermo Scientific equipment, Warrington, UK). Fourier Transform Infrared Spectroscopy (FTIR) was recorded to examine the chemical binding nature of the synthesized products using a Bruker IR spectrometer (Bruker Optics, Victoria, Australia). The morphology and size of the $\mathrm{CuO}$ nanowires were characterized while using a Field Emission-Scanning Electron Microscopy (FE-SEM, Hitachi model S3000-H), Hitachi Science \& Technology, UK and High Resolution-Transmission electron microscopy (HR-TEM, TECNAI $\mathrm{G}^{2}$ 20), FEI Company, Hillsboro, OR, USA.

\section{Results and Discussion}

\subsection{XRD Patterns of the CuO Nanowires}

The phase purity and structural characteristics of the synthesized $\mathrm{CuO}$ nanowires were carried out using XRD analysis, which are shown in the Figure 1. The XRD Diffraction patterns appeared at $2 \theta\left(32.45^{\circ}, 35.57^{\circ}, 38.69^{\circ}, 48.77^{\circ}, 53.57^{\circ}, 58.75^{\circ}, 61.72^{\circ}, 66.04^{\circ}, 68.24^{\circ}\right.$ and $\left.75.16^{\circ}\right)$ values and they were assigned to the corresponding (110), (002), (111), (112), (020), (202), (113), (310), (220) and (004) planes, respectively.

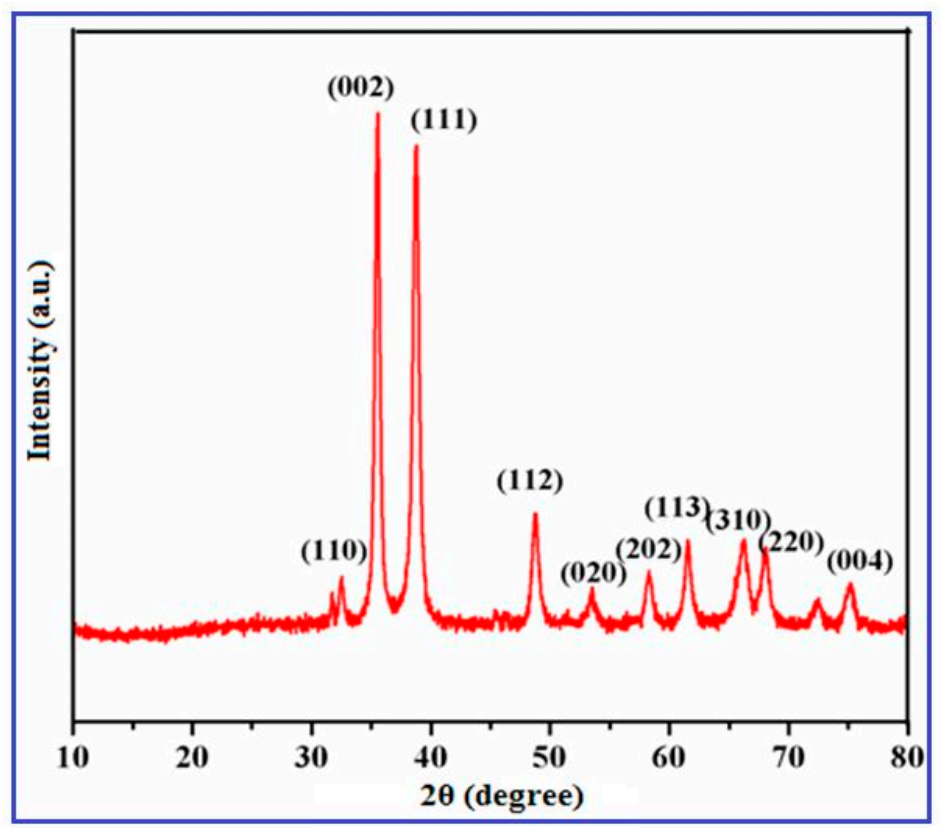

Figure 1. X-ray diffractometry (XRD) pattern of copper oxide $(\mathrm{CuO})$ nanowires synthesized using SMFE. 
The obtained XRD patterns indicated that the synthesized nanowires are highly crystalline with monoclinic structure of $\mathrm{CuO}$, which was confirmed by the Joint Committee on Powder Diffraction Standards (JCPDS) (Card No.: 89-5895). The other impurity products like $\mathrm{Cu}(\mathrm{OH})_{2}$ and $\mathrm{Cu}_{2} \mathrm{O}$ characteristic peaks were not observed, revealing the phase pure formation of $\mathrm{CuO}$ nanowires [32]. The peak broadening also noticeably signifies the development of smaller sized $\mathrm{CuO}$ nanowires. The average crystallite size of the $\mathrm{CuO}$ particles that were synthesized by this greener approach was estimated to be ca. $46.2 \mathrm{~nm}$ by using the Debye-Scherrer formula, $D=K \lambda / \beta \cos \theta$. These diffraction patterns appeared in this study are similar to those previously reported literatures about the eco-friendly preparation of $\mathrm{CuO}$ nanoparticles [33,34]. The XRD results further indicate that the $\mathrm{CuO}$ nanowires synthesized through this biosynthesis method constitute single-phase growth with high degree of purity and confirmed the existence of $\mathrm{CuO}$.

\subsection{XPS Spectra of the $\mathrm{C} u \mathrm{O}$ Nanowires}

XPS spectra were performed to analyze the chemical states of transition metals, including their localized valence d-orbitals. Figure 2 illustrates the core level $\mathrm{Cu} 2 \mathrm{p}$ high-resolution photoemission spectra of the $\mathrm{CuO}$ nanowires synthesized using SMFE. As shown in the XPS spectra, the binding energy emerged at around $936.5 \mathrm{eV}$ and $956.4 \mathrm{eV}$ are corresponding to the core level peaks of $\mathrm{Cu} 2 \mathrm{p}_{3 / 2}$ and $\mathrm{Cu} 2 \mathrm{p}_{1 / 2}$ that are present in the pure phase of $\mathrm{CuO}$ nanowires.

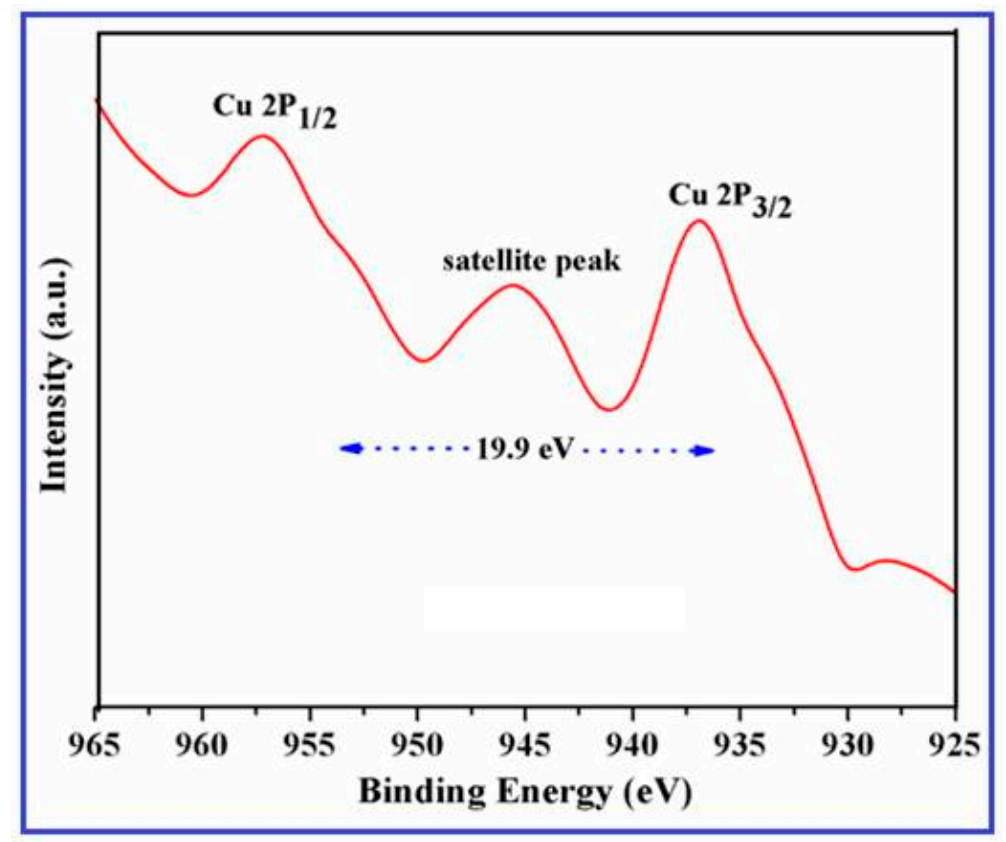

Figure 2. Core level X-Ray Photoelectron Spectrometer (XPS) spectral peaks of CuO nanowires synthesized using Sapindus mukorossi fruit extract (SMFE).

The emergence of strong satellite peak and the binding energy gap value $(19.9 \mathrm{eV})$ between the $\mathrm{Cu} 2 \mathrm{p}_{3 / 2}$ and $\mathrm{Cu} 2 \mathrm{p}_{1 / 2}$ peaks is differentiated from the pure $\mathrm{Cu}$ or $\mathrm{Cu}_{2} \mathrm{O}$, which also explores the existence of an unfilled $\mathrm{Cu} 3 \mathrm{~d}^{9}$ shell, further confirming the presence of $\mathrm{Cu}^{2+}$ ions in the $\mathrm{CuO}[35,36]$. The XPS results are also very well matched with the XRD pattern in Figure 1, and they confirm that the synthesized nanowires comprising a pure phase of $\mathrm{CuO}$.

\subsection{FTIR Spectra of the $\mathrm{CuO}$ Nanowires}

The $\mathrm{CuO}$ nanowires were subjected to FTIR analysis at room temperature to evaluate the chemical composition and to confirm the formation of $\mathrm{CuO}$, which are recorded in the range of $400-4000 \mathrm{~cm}^{-1}$. FTIR spectra of $\mathrm{CuO}$ nanowires synthesized using SMFE are shown in Figure 3. 


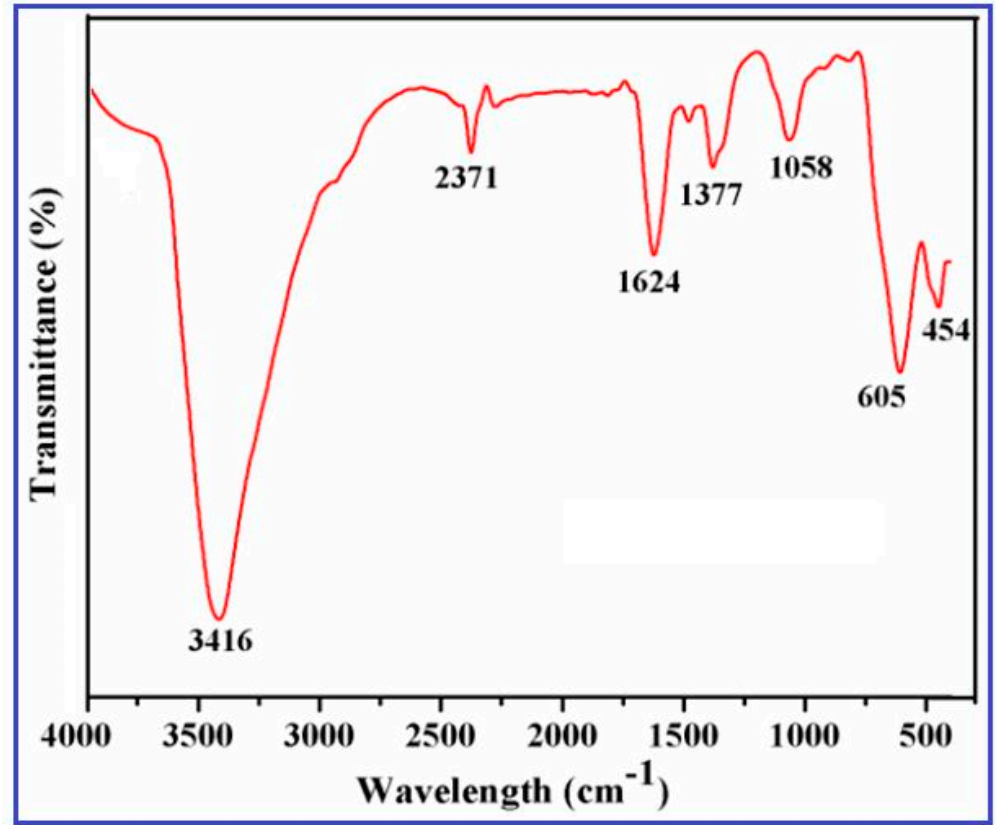

Figure 3. Fourier Transform Infrared Spectroscopy (FTIR) spectra of CuO nanowires synthesized using SMFE.

The two important ant characteristic bands appeared at around $454.5 \mathrm{~cm}^{-1}$ and $605.7 \mathrm{~cm}^{-1}$ can be assigned to the $A_{u}$ and $B_{u}$ modes of $C u O$, respectively [37]. These high-frequency modes of $A_{u}$ and $B_{u}$ can be assigned to the $\mathrm{Cu}-\mathrm{O}$ stretching vibration along the [1 01 1] direction [38]. An intense broad band appeared in the $3200-3550 \mathrm{~cm}^{-1}$ region that was attributed to the $\mathrm{O}-\mathrm{H}$ stretching vibration of surface hydroxyl groups of adsorbed water molecules [39], which arises because nanocrystalline materials having a high surface-to-volume ratio absorbs high moisture. The small band at approximately $2371 \mathrm{~cm}^{-1}$ is due to $\mathrm{O}=\mathrm{C}=\mathrm{O}$ stretching vibration. The sharp absorption band appeared at around $1624 \mathrm{~cm}^{-1}$ can be ascribed to the $\mathrm{C}=\mathrm{C}$ aromatic bending vibration of alkenes present in the SMFE [40] and also implies the formation of bidentate ligand coordination expected between $\mathrm{C}-\mathrm{O}$ and $\mathrm{Cu}(\mathrm{II})$ of $\mathrm{CuO}$. The IR band that appeared at around $1058 \mathrm{~cm}^{-1}$ can be attributed to $\mathrm{C}-\mathrm{OH}$ stretching and $\mathrm{OH}$ bending vibration, indicating the existence of a greater number of hydroxyl groups in the chemical structure of SMFE. The IR bands observed in the above-mentioned regions confirmed the formation of $\mathrm{CuO}$ in the nanophase, which is also reported by the several researchers [41]. The transmittance peak appeared at around $1377 \mathrm{~cm}^{-1}$ may be ascribed due to the presence of $\mathrm{CO}_{2}$, which is usually adsorbed from the air on the surface of sample materials during $\mathrm{KBr}$ pelletization.

\subsection{FE-SEM Pictures of the CuO Nanowires Synthesized Using SMFE}

FE-SEM analysis was performed to investigate the surface morphology and dimension of the as-prepared $\mathrm{CuO}$ nanowires. The FE-SEM images that were taken at low and high magnification for the $\mathrm{CuO}$ nanowires are shown in Figure 4a,b.

From the observed images, it can be inferred that the $\mathrm{CuO}$ nanostructures possess a variabledimension wire-like morphology. It can also be demonstrated that the final products consist of large number of $\mathrm{CuO}$ nanowires of approximately $800 \mathrm{~nm}$ in length and 50-100 $\mathrm{nm}$ in width that are made up of several small nanowires with a width of about $10 \mathrm{~nm}$, forming a uniform one-dimensional (1D) nanostructure. Clearly, $\mathrm{CuO}$ nanowires could be produced in large quantities using this facile method. 


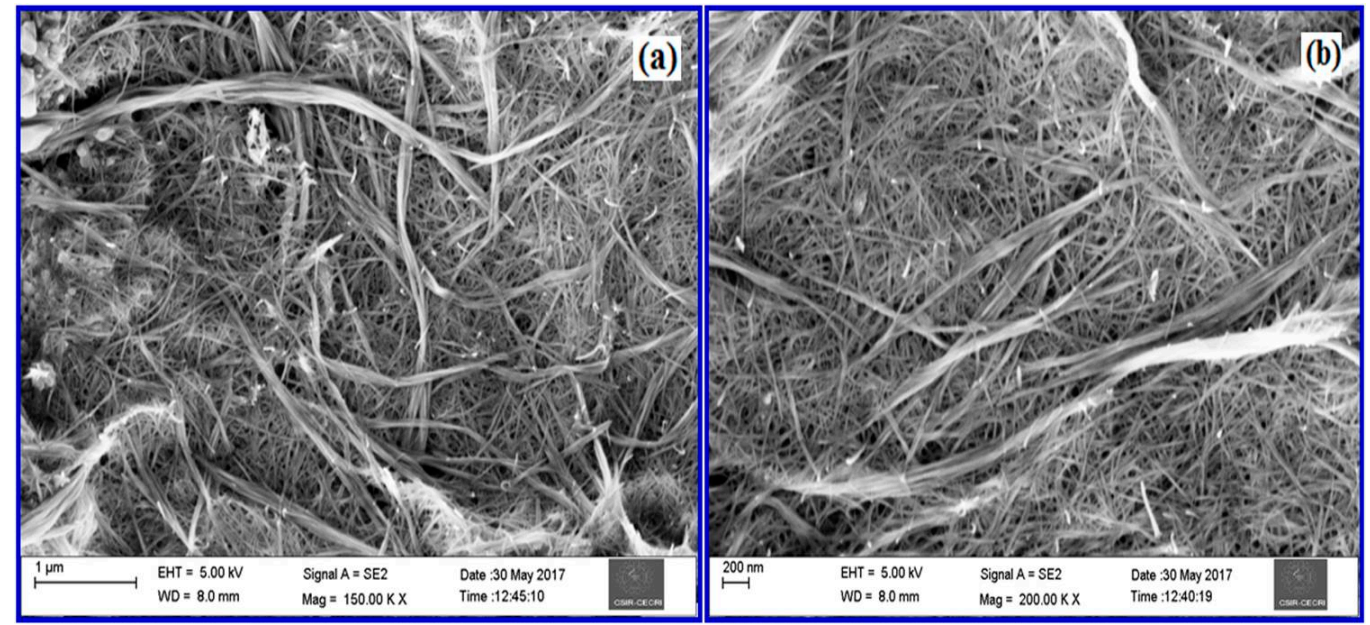

Figure 4. Field Emission-Scanning Electron Microscopy (FE-SEM) micrographs of CuO nanowires prepared using SMFE (a) low magnification (150.00 KX) and (b) high magnification (200.00 KX).

\subsection{HR-TEM Pictures of the CuO Nanowires Synthesized Using SMFE}

We have examined the microstructure and crystallinity of the $\mathrm{CuO}$ nanowires that were grown on the copper grids by HR-TEM and selected area electron diffraction (SAED). Figure 5a,b shows typical HR-TEM and SAED images of discrete $\mathrm{CuO}$ nanowires, respectively.
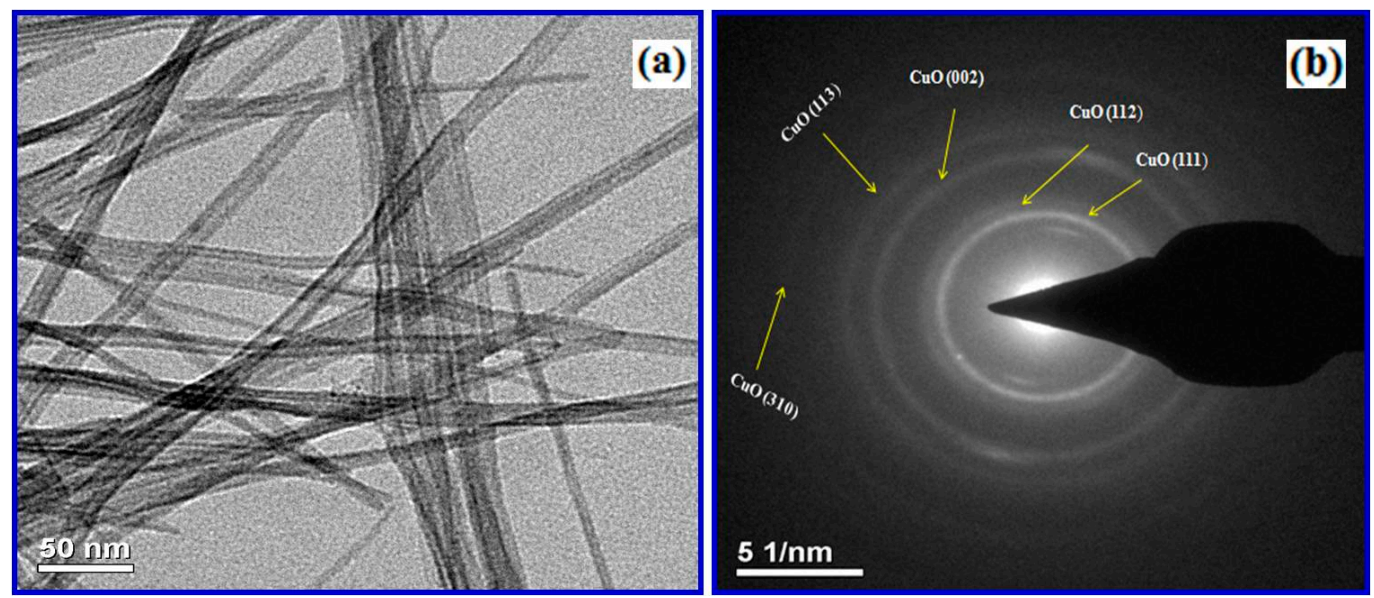

Figure 5. (a) High Resolution-Transmission electron microscopy (HR-TEM) micrographs of CuO nanowires synthesized using SMFE and (b) selected area electron diffraction (SAED) pattern of corresponding micrograph.

A wire-like morphology was observed for the $\mathrm{CuO}$ nanostructures that were synthesized using SMFE, which is given in the Figure $5 \mathrm{a}$ and the observed image is also agreed well with the FE-SEM images shown in the Figure 4a,b. Figure 5a illustrated that the diameters of as-obtained nanowires are uniform along the length of nanowires. The main parts of the nanowires are straight, lacking any perceptible tapering at the ends and without any clustering at the tip with a smooth morphology. Figure $5 b$ shows the SAED patterns that were recorded when the electron beam was focused on an individual nanowire shown in Figure 5a. The ring pattern indicates that these $\mathrm{CuO}$ nanowires are randomly oriented, and the strong intensities reveal the high crystallinity of the sample. All of the obtained rings in SAED may be assigned to the diffraction peaks of monoclinic structure of $\mathrm{CuO}$ rather than those of $\mathrm{Cu}_{2} \mathrm{O}$ and $\mathrm{Cu}$, indicating that the obtained nanowires are in the pure phase of $\mathrm{CuO}$. Furthermore, the indexed diffraction rings can be attributed to the five major crystal planes, (111), (112), (002), (113) and (310), of monoclinic CuO, corroborating with the XRD results [42]. 


\subsection{Growth Mechanisms of $\mathrm{CuO}$ Nanowires}

Anisotropic nanostructures, such as nanoribbons, nanowires, nanotubes, nanobelts, nanoleaves, nanorods and nanorods, etc., have attracted immense interest in various applications, because of their unique electronic, chemical, optical and electrocatalytic properties. Therefore, it is highly desirable to synthesize morphology controlled nanostructured materials by various preparation methods. However, such procedures are lengthy and difficult to accomplish with good control over the crystallinity and phase purity of the nanomaterials. To alleviate the above discussed limitations, for the first time the SMFE (bio-surfactant) was employed to synthesize the controlled and directed growth of $\mathrm{CuO}$ nanowires, like morphology through greener approach. In addition, SMFE played a though provoking role by generating a large number of well-defined $\mathrm{CuO}$ nanowires have been fabricated by the template free bio-surfactant assisted method, and the suggested formation mechanism of 1D nanowire like morphology is illustrated in Scheme 1.

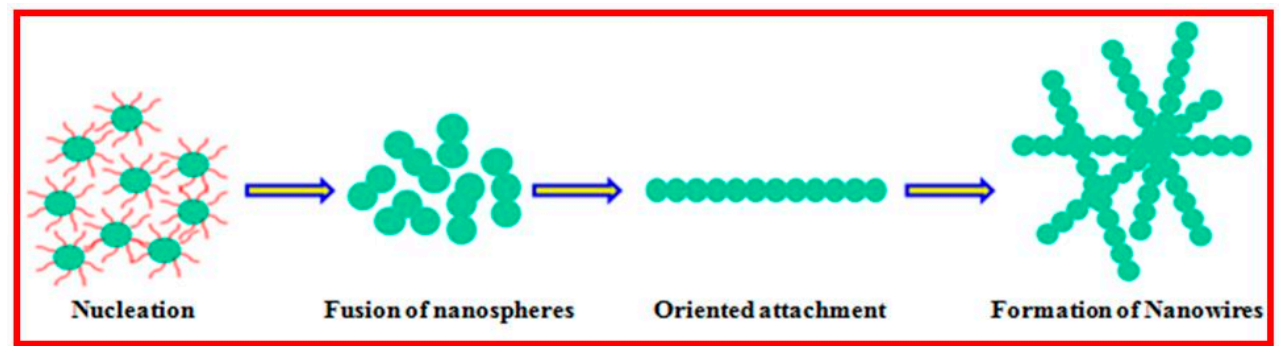

Scheme 1. A possible mechanism for the growth of nanospheres into nanowire.

The 1D nanostructure formation is an integrated process of nucleation, coalescence, oriented attachment and growth. The aqueous extract of SMFE mainly contains saponin rich compounds, like sapindoside $A$, sapindoside $B$, sapindoside $C$ and sapindoside $D$, as well as Mukorossi saponins E1 and Y1, which have many -OH groups, and these compounds act as structure-directing agents, and induces copper hydroxide nanowires, like morphology, some of the chemical structures of saponin present in the SMFE is given in the Figure 6 [31]. Subsequently, the biosurfactant molecules present in the SMFE act as a shape inducing agent for the evolution process of the $\mathrm{CuO}$ nanowires, as seen from the FE-SEM and TEM images (Figures 4 and 5).

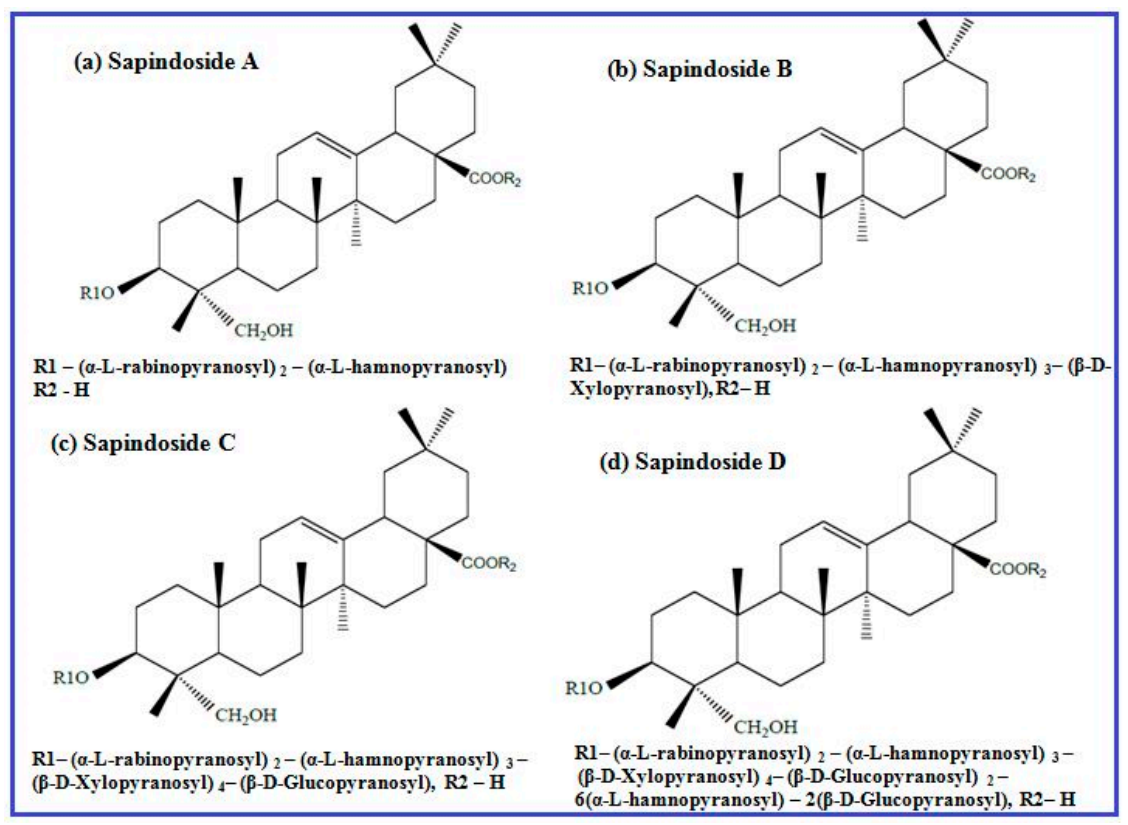

Figure 6. Chemical Structure of different types of saponin present in the SMFE. 
In an aqueous solution, a simple chemical reaction takes place between precursor $\left(\mathrm{CuSO}_{4} \cdot 6 \mathrm{H}_{2} \mathrm{O}\right)$ and the alkali $(\mathrm{NaOH})$ by the precipitation of the intermediate product Copper(II) hydroxide $\left(\mathrm{Cu}(\mathrm{OH})_{2}\right)$, acts as a building unit for the tailoring of $\mathrm{CuO}$ nanocrytals. It may be assumed that, at an earlier period of reaction time, $\mathrm{Cu}(\mathrm{OH})_{2}$ units are produced by the addition of a smaller amount of $\mathrm{NaOH}$, however it is insufficient to produce $\mathrm{OH}^{-}$ions. By exploiting the SMFE having big polar head and long hydrocarbon chain with large number of hydroxyl $(-\mathrm{OH})$ groups, thus facilitates the building up of the nano-architecture of copper oxide with different shapes. Moreover, the slow hydrolysis of transition metal salts helps the organic moiety to control the branching of building blocks lead to a guided 1D growth. Thus, during the formation process of $\mathrm{Cu}(\mathrm{OH})_{2}$ units along with the SMFE, it is evident to generate larger amount of complex anionic product $\mathrm{Cu}(\mathrm{OH})_{4}{ }^{2-}$. It is also believed that a large amount of $\left(\mathrm{Cu}(\mathrm{OH})_{2}\right)$ nanospheres might be produced by the dehydration of $\left[\mathrm{Cu}(\mathrm{OH})_{4}\right]^{2-}$ ions and it serves as a nucleating embryo for further growth of nanowire formation through oriented attachment mechanism. The involvement of higher amount of hydroxyl groups induced by the big polar hydrophilc head and long chain hydrocarbon tail of saponin compounds in SMFE can markedly promote the growth of $1 \mathrm{D}$ nanowires formation from the initially developed $\left(\mathrm{Cu}(\mathrm{OH})_{2}\right)$ nanodots/nuclei [43]. It seems that the participation of the bio-surfactant not only renders the $\left[\mathrm{Cu}(\mathrm{OH})_{4}\right]^{2-}$ ions, but also accelerates the 1D nanostructure in a particular direction [44]. Moreover, the concentration of hydroxyl groups are essential for the oriented attachment of $\left(\mathrm{Cu}(\mathrm{OH})_{2}\right)$ nanodots into a linear chain through a crystallographic orientation [45]. Finally, at the calcinations process of $\mathrm{Cu}(\mathrm{OH})_{2}$ nanowires, thermal decomposition occurs by forming $\mathrm{CuO}$ nanowires like structure. From these observations, it is concluded that the high surface energy of the initially formed nanodots linearly attached through particular planes is driven by the existence of organic molecules in the SMFE, and the dipolar attraction originates from the opposite polarity of the crystal planes $(<002>$ and $<111>$ ) directed towards the $\mathrm{CuO}$ nanowires.

\subsection{Electrochemical Investigations of the $\mathrm{CuO}$ Nanowires}

All of the electrochemical measurements were recorded using a $\mathrm{CHI}$ model 660 potentiostat $(\mathrm{CH}$ Instruments, Austin, TX, USA) equipped with a common three-electrode assembly, including glassy carbon electrode (GCE) as the working electrode, a platinum wire and saturated calomel $(\mathrm{Ag} / \mathrm{AgCl})$ electrodes were used as the counter and reference electrode, respectively. Prior to the modification, the GCE electrode was polished with different grades $(0.3 \mu \mathrm{m}$ and $1 \mu \mathrm{m})$ of alumina slurry and ultrasonically rinsed with water and ethanol for the removal of adsorbed impurities. About $4 \mathrm{mg}$ of $\mathrm{CuO}$ nanoparticles were suspended in a mixture of $1 \mathrm{~mL}$ water and $0.2 \mathrm{~mL}$ nafion undergoes sonication for 10 mins until the appearance of syrupy black colored solution. CuO nanowires suspension $(10 \mu \mathrm{L})$ of the dispersed sample was drop casted on the surface of the pre-cleaned GCE and it serves as a working electrode. The cyclic voltammetry $(\mathrm{CV})$ measurements were carried out from $-0.2 \mathrm{~V}$ to $0.4 \mathrm{~V}$ (vs. $\mathrm{Ag} / \mathrm{AgCl}$ ) at a scan rate of $50 \mathrm{mV} \cdot \mathrm{s}^{-1}$ in $0.1 \mathrm{M}$ PBS, $\mathrm{pH}$ 7.4. The differential pulse voltammetry (DPV) studies were performed from the potential range $-0.2 \mathrm{~V}$ to $0.4 \mathrm{~V}$ (vs. Ag/ $\mathrm{AgCl}$ ), at a preset pulse width of 0.05 , pulse period of $0.5 \mathrm{~s}$, and pulse amplitude of $0.05 \mathrm{~V}$. DPV technique was also used in the multipotential modality to indentify the other interfering biomolecules. Chronoamperometry (CA) study of the modified GCE with the consecutive addition of the common interfering species was carried in $0.1 \mathrm{M}$ phosphate buffer ( $\mathrm{pH} 7.4$ ) at a given potential of $0.15 \mathrm{~V}$ (vs. Ag/ $\mathrm{AgCl}$ ).

\subsection{Electrochemical Sensing Behavior of the CuO Nanowire/GCE for Dopamine}

To examine the electrocatalytic response of $\mathrm{CuO}$ nanowires synthesized using SMFE, it has been exploited for their intriguing properties on the electrochemical sensing of DA on $\mathrm{CuO}$ nanowires/GCE. The cyclic voltammograms of $0.2 \mathrm{mM}$ DA on the bare GCE and the $\mathrm{CuO}$ nanowires/GCE in the potential range of $-0.2 \mathrm{~V}$ to $+0.4 \mathrm{~V}$ at a scan rate $50 \mathrm{mV} / \mathrm{s}$ are illustrated in the Figure 7 . No characteristic redox behavior was observed for the bare GCE (Figure 7a), whereas the CuO nanowires/GCE displayed a small background current (Figure 7b) in the PBS (0.1 M). 


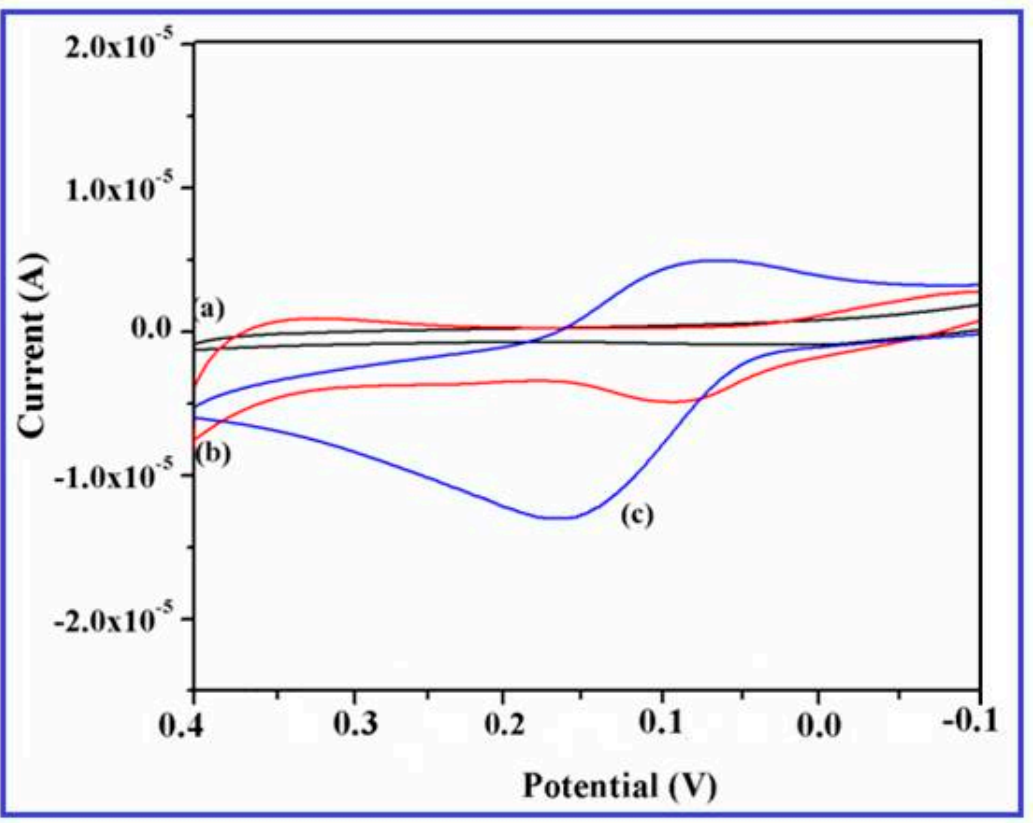

Figure 7. Cyclic voltammograms of (a) unmodified glassy carbon electrode (GCE), (b) $\mathrm{CuO}$ nanowires/GCE in PBS (pH 7.4), and (c) CuO nanowire/GCE at $0.2 \mathrm{mM}$ DA dissolved in $0.1 \mathrm{M}$ phosphate buffer ( $\mathrm{pH} 7.4$ ) solution recorded at a scan rate $50 \mathrm{mV} / \mathrm{s}$.

This tremendous redox behavior of DA revealed the excellent electrocatalytic activity and large surface to volume ratio of the $\mathrm{CuO}$ nanowires that were coated on the electrode surface. However, after the addition of $0.2 \mathrm{mM}$ DA, a pair of well-defined redox peaks is observed at an anodic oxidation potential of $0.18 \mathrm{~V}$ and cathiodic reduction potential of $0.13 \mathrm{~V}$ with a dramatic increment of current response (Figure 7c). These results specified that the SMFE assisted $\mathrm{CuO}$ nanowires significantly enhances the electrochemical property of the modified electrode, which may be ascribed to the higher surface energy, large available surface area, and improved electron transfer reaction of the $\mathrm{CuO}$ nanowires on the GC electrode [46]. Moreover, it also demonstrated that the effective electroactive surface area of the electrode was considerably increased by employing the $\mathrm{CuO}$ nanowires as a electrode material, it may be attributed to the anticipated involvement of surface species $(\mathrm{Cu}$ (II) $/ \mathrm{Cu}$ (III) ions) during the electrocatalytic oxidation towards DA.

\subsection{Redox Behavior of Dopamine}

The presence of negatively charged free surface hydroxyl groups of $\mathrm{CuO}$ nanowires have been confirmed through FTIR study. These surface hydroxyl $(-\mathrm{OH})$ groups preferentially undergoes chemical bonding with the positively charged amine $\left(-\mathrm{NH}_{2}\right)$ groups of dopamine at the physiological $\mathrm{pH}$ 7.4, which could form hydrogen bond and facilitate the electron transfer reaction of DA. Also, the stimulated conducting activity of $\mathrm{CuO}$ nanowires on the specified potential greatly increased the magnitude of current response than the bare GCE. When an appropriate potential is applied to the $\mathrm{CuO}$ nanowires/GCE, it demonstrates that the electrochemical oxidation reaction of DA occurs by exchanging the two electron and two protons, and thus the dopamine-o-quinone was formed [47]. According to the above conversation and the well known fact, the electrocatalytic oxidation behavior of DA on $\mathrm{CuO}$ nanowires/GCE can be elucidated by Scheme 2 . 


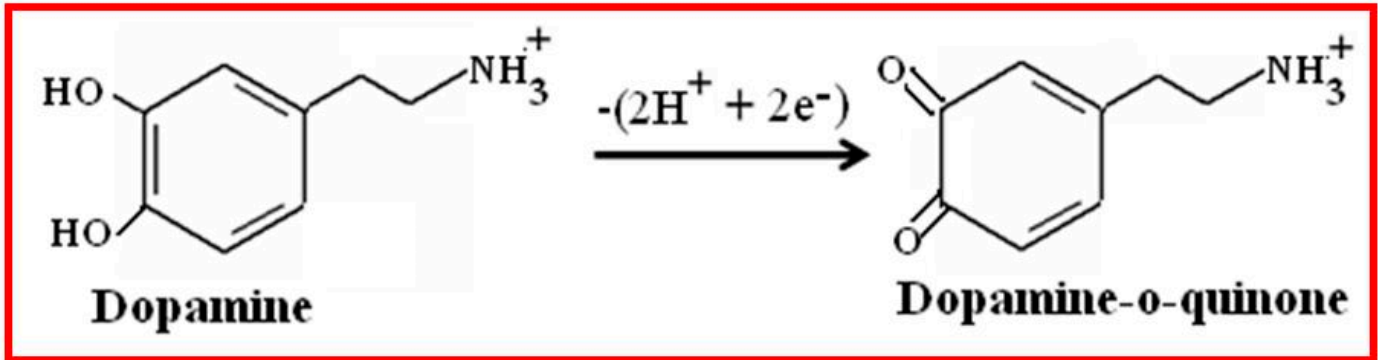

Scheme 2. Electrochemical Oxidation Mechanism of Dopamine on $\mathrm{CuO}$ nanowires/GCE.

\subsection{Influence of the Scan Rate on the Detection of Dopamine}

The electrochemical response of the $\mathrm{CuO}$ nanowire/GCE in $0.2 \mathrm{mM}$ dopamine with the effect of the scan rate is shown in the Figure 8a. The oxidation and reduction peak currents simultaneously increased with the increasing scan rate from $10 \mathrm{mV} / \mathrm{s}$ to $100 \mathrm{mV} / \mathrm{s}$ and its corresponding calibration plots of the oxidation peak current vs. square root of scan rate are given in the Figure $8 \mathrm{~b}$, which illustrates the linear toward various scan rates on the modified electrode.

It can also be seen that the oxidation and reduction peak potentials shifted toward more positive and negative direction, respectively. The correlation coefficient corresponding to the anodic peak current was 0.9791, which indicates that the diffusion processes control the overall kinetics [48]. In the determined range of scan rate, the oxidation peak current linearly plotted to the square root of the scan rate and the peak separation became larger with the increase of scan rate. It can also be seen that the potential gap between oxidation and reduction peak current did not significantly shift, exhibiting the enhanced electrochemical activity was performed on the $\mathrm{CuO}$ nanowires/GCE.

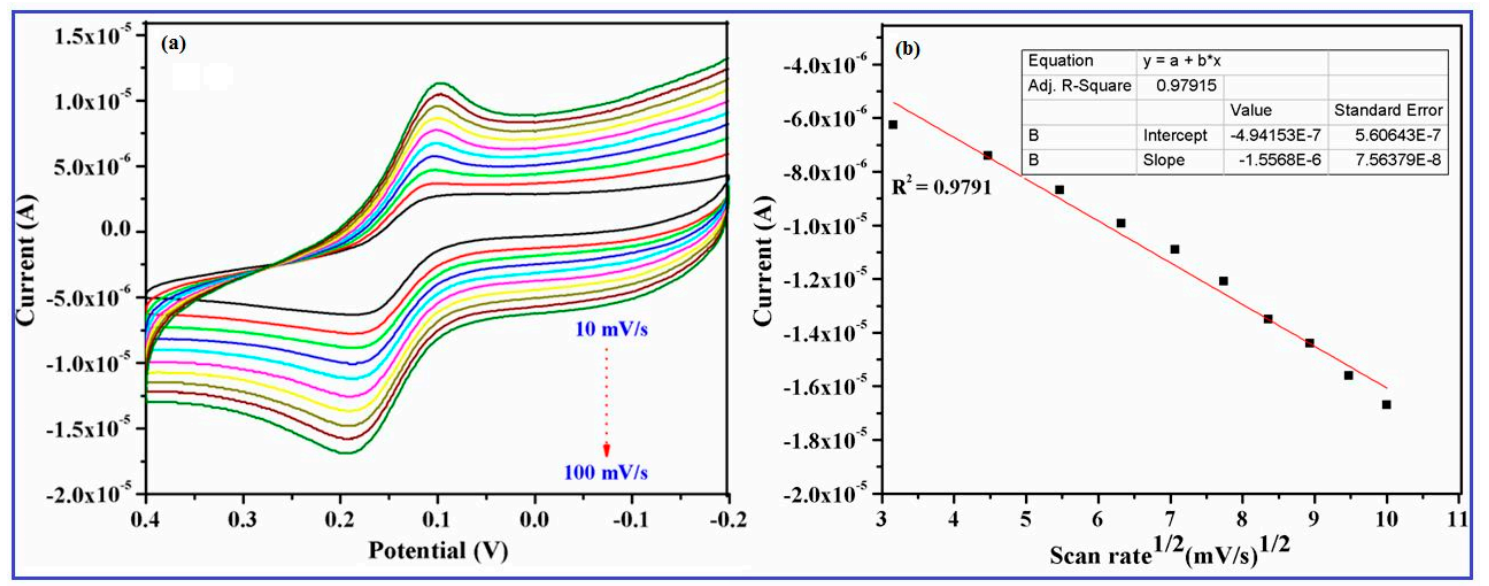

Figure 8. Cyclic voltammetric responses of $\mathrm{CuO}$ nanowires/GCE in the presence of $0.2 \mathrm{mM}$ DA in 0.1 M phosphate buffer (pH 7.4) (a) at different scan rates $(10 \mathrm{mV} / \mathrm{s}$ to $100 \mathrm{mV} / \mathrm{s})$ and (b) calibration curve plotted versus square root of the scan rate and oxidation current.

\subsection{Effect of Dopamine Concentration on the $\mathrm{C} u O$ Nanowires/GCE}

The DPV method can be used to determine the electrocatalytic activity of DA because of the high current sensitivity and resolution of this technique. An excellent electrochemical performance of the green synthesized $\mathrm{CuO}$ nanowires for the determination of $\mathrm{DA}$ was also demonstrated through the DPV measurements in $0.1 \mathrm{M}$ PBS with various concentrations $(0.1 \mu \mathrm{M}$ to $0.105 \mathrm{mM})$ of DA, which are shown in the Figure 9a. 


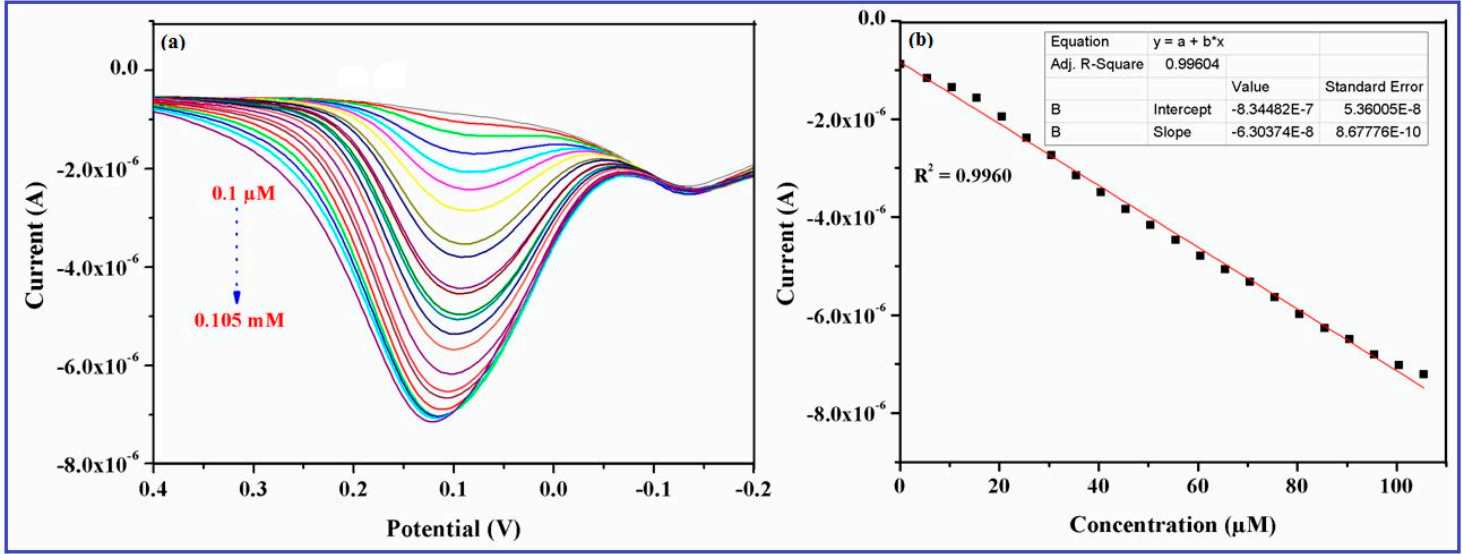

Figure 9. Differential pulse voltammetry (DPV) responses obtained for various concentrations of DA $(0.1 \mu \mathrm{M}$ to $0.105 \mathrm{mM})$ in $0.1 \mathrm{M}$ phosphate buffer $(\mathrm{pH} 7.4)$ at a fixed scan rate $50 \mathrm{mV} / \mathrm{s}(\mathrm{a}) \mathrm{CuO}$ nanowires/GCE and (b) calibration curve plotted versus oxidation current and the molar concentration of dopamine (DA).

The result indicated that anodic oxidation current successively increased with the increasing concentration of DA in the PBS, which proves the electrocatalytic response of the modified electrode for DA sensing is highly concentration dependent [49]. This type of immediate response on the electrode implies that the material ( $\mathrm{CuO}$ nanowires) efficiently provides the well-defined voltammetric signals by promoting the redox behavior of DA. Figure $9 \mathrm{~b}$ illustrates the relationship between the different concentrations of DA and the corresponding anodic peak currents, with a correlation coefficient of 0.9960. The obtained result indicates that the detection of very low concentrations of DA is possible on the $\mathrm{CuO}$ nanowires/GCE and the proposed biosensor showed a wide linear range of DA from $0.1 \mu \mathrm{M}$ to $0.105 \mathrm{mM}$, with an acceptable sensitivity and limit of detection of $0.1 \mu \mathrm{M}$. The oxidation current response became saturated at a concentration of $0.10 \mathrm{mM}$, which may be accredited to the availability of a large number of nanowires with higher electro-active surface area, promotes electron transfer reaction of DA. In addition, the sensing performance of the newly designed biosensor was also compared for the detection of DA with the various nanostructured electrode materials. The linear range, detection limits (LOD), optimal $\mathrm{pH}$ of the electrolyte, and techniques used for the other electrode materials are summarized in Table 1, and the $\mathrm{CuO}$ nanowire/GCE showed better electrochemical performance than the previously reported DA biosensors.

Table 1. Comparison of some dopamine sensors based on different electrode materials.

\begin{tabular}{|c|c|c|c|c|c|}
\hline Electrode Material & Technique & LOD & Linear Range & Electrolyte & Ref. \\
\hline Au-graphene & DPV & $1.86 \mathrm{mM}$ & 5-1000 mM & $\mathrm{pH} 6.0$ & [50] \\
\hline Graphene & DPV & $2.64 \mathrm{mM}$ & 4-100 mM & $\mathrm{pH} 7.0$ & [51] \\
\hline 3D-GN@WO 3 nanowire & CA & $238 \mu \mathrm{M}$ & 10-150 mM & $\mathrm{pH} 6.0$ & [52] \\
\hline $\mathrm{Au}-\mathrm{Cu}_{2} \mathrm{O} / \mathrm{rGO}$ & DPV & $3.9 \mu \mathrm{M}$ & 10-90 $\mu \mathrm{M}$ & $\mathrm{pH} 7.0$ & [53] \\
\hline $\mathrm{GO}$ & DPV & $0.27 \mathrm{mM}$ & $1-15 \mathrm{mM}$ & pH 5.0 & [54] \\
\hline $\mathrm{Au} / \mathrm{RGO} / \mathrm{GCE}$ & DPV & $1.40 \mu \mathrm{M}$ & $6.8-41 \mu \mathrm{M}$ & $\mathrm{pH} 7.0$ & [55] \\
\hline $\mathrm{NiO}-\mathrm{CuO} / \mathrm{GR} / \mathrm{GCE}$ & SWV & $0.167 \mu \mathrm{M}$ & $0.5-20 \mu \mathrm{M}$ & $\mathrm{pH} 8.0$ & [56] \\
\hline RGO-Pd-NPs & LSV & $0.23 \mu \mathrm{M}$ & $1-150 \mu \mathrm{M}$ & $\mathrm{pH} 7.0$ & [57] \\
\hline Rod shaped CuO nanoparticles/MCPE & DPV & $0.18 \mu \mathrm{M}$ & $0.3-1.4 \mu \mathrm{M}$ & $\mathrm{pH} 6.0$ & [58] \\
\hline $\mathrm{Ag} / \mathrm{RGO}$ & LSV & $5.4 \mu \mathrm{M}$ & $10-800 \mu \mathrm{M}$ & $\mathrm{pH} 6.0$ & [59] \\
\hline $\mathrm{CuO} / \mathrm{MWNTs} /$ Nafion/GCE & DPV & $0.4 \mu \mathrm{M}$ & $1.0-80 \mu \mathrm{M}$ & $\mathrm{pH} 6.0$ & [60] \\
\hline $\mathrm{ZnO} / \mathrm{MWNTs} / \mathrm{GCE}$ & $\mathrm{CV}$ & $3 \mu \mathrm{M}$ & $3-200 \mu \mathrm{M}$ & $\mathrm{pH} 7.0$ & [61] \\
\hline $\mathrm{CuO}$ nano-rice/GCE & DPV & $0.42 \mu \mathrm{M}$ & $1-150 \mu \mathrm{M}$ & $\mathrm{pH} 7.0$ & [62] \\
\hline GR-SnO $2 /$ CILE & DPV & $0.5 \mu \mathrm{M}$ & $5-500 \mu \mathrm{M}$ & $\mathrm{pH} 6.0$ & [63] \\
\hline N-doped graphene & DPV & $0.25 \mu \mathrm{M}$ & $0.5-170 \mu \mathrm{M}$ & $\mathrm{pH} 6.0$ & [64] \\
\hline GR-CS/GCE & DPV & $5 \mu \mathrm{M}$ & $15-175 \mu \mathrm{M}$ & $\mathrm{pH} 7.0$ & [65] \\
\hline $\mathrm{CuO}$ nanowire/GCE & DPV & $0.1 \mu \mathrm{M}$ & $0.1-105 \mu \mathrm{M}$ & $\mathrm{pH} 7.4$ & This work \\
\hline
\end{tabular}




\subsection{Anti-Interference/Selectivity Study on the CuO Nanowires/GCE}

In order to assess the selectivity and response of the $\mathrm{CuO}$ nanowire/GCE in the presented DA sensor, examination of the electrocatalytic properties with the influence of common interfering biomolecules/species, such as $\mathrm{AA}, \mathrm{UA}, \mathrm{CA}, \mathrm{NaCl}$, and glucose was evaluated by using chronoamperometry at a detection potential of $+0.15 \mathrm{~V}$. Figure 10 displays the amperometric response to the consecutive additions of $0.1 \mathrm{mM}$ of $\mathrm{DA}$, glucose, $\mathrm{AA}, \mathrm{CA}, \mathrm{UA}$, and $\mathrm{NaCl}$ in $0.1 \mathrm{M}$ PBS (pH 7.4) solution.

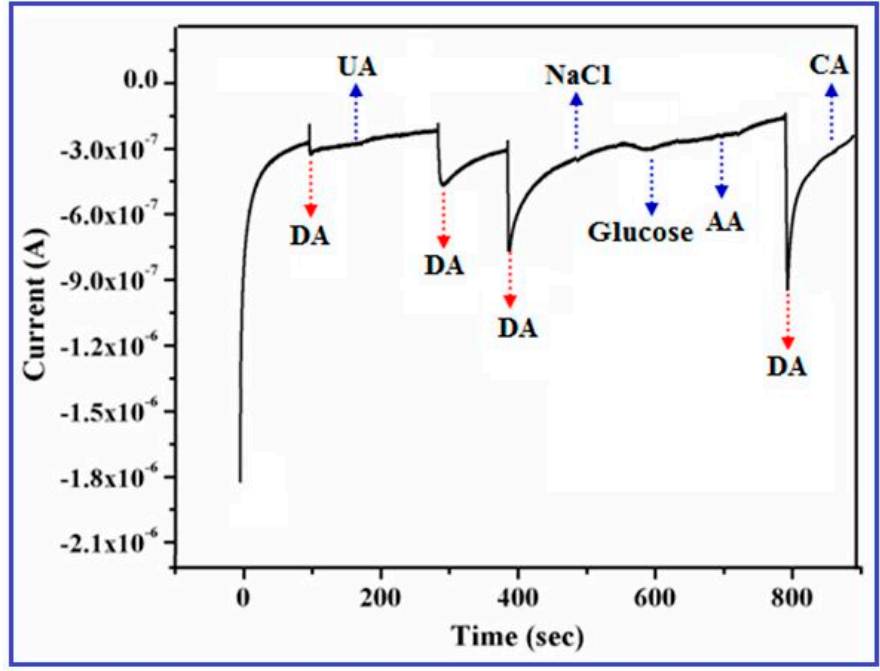

Figure 10. Interference study of the $\mathrm{CuO}$ nanowires/GCE recorded in $0.1 \mathrm{M}$ phosphate buffer (pH 7.4) at a fixed potential of $0.15 \mathrm{~V}$ with the existence of $\mathrm{UA}, \mathrm{NaCl}, \mathrm{AA}$, glucose and $\mathrm{CA}$.

The outcome of the experimental result represents that the above interfering species did not show any remarkable change in the oxidation current response of DA that explored the outstanding selectivity of the proposed sensor. Further, the anodic current response occurred by DA is extremely higher than the other interfering species (AA, glucose, $\mathrm{CA}, \mathrm{NaCl}$ and UA), which implies good selectivity and sensitivity of $\mathrm{CuO}$ nanowires/GCE towards the quantitative analysis of DA even in the presence of general physiological interfering biomolecules.

\subsection{Selectivity Study on the CuO Nanowires/GCEusing CV and DPV}

Interference study was further examined by CV and DPV using possible interferents, such as UA, AA, CA, Glucose, and $\mathrm{NaCl}$ for the selective determination of DA. It can be seen that both the CV and DPV curves exhibited the similar electrochemical responses on the modified GCE. Figure 11A,B represents the CV and DPV curves of individual UA, AA, DA, CA, Glucose, $\mathrm{NaCl}$ and their mixture at the $\mathrm{CuO}$ nanowires/GCE in pH 7.0 PBS, it can be noted that a pair of redox peak is appeared for DA and the common interfering species, like UA and AA, showed small oxidation current, whereas other species does not observe any redox behavior on the modified GCE. On the other hand, the electrochemical reaction of the mixture species exhibited only clear redox behavior of DA and hinders the oxidation process of UA and DA. Therefore, we confirmed that it can clearly detect the remarkable enhancement of DA redox behavior at $\mathrm{CuO}$ nanowires/GCE with the presence of possible concomitants and it promotes the selective determination of DA. 


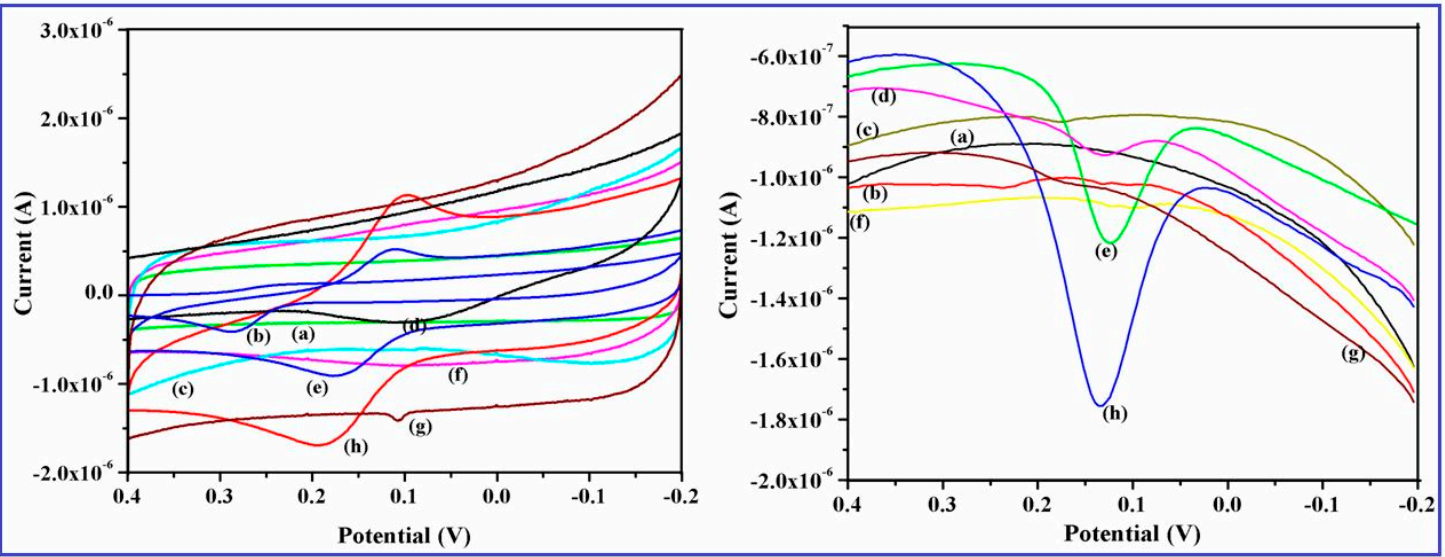

(A)

(B)

Figure 11. Interference studies on $\mathrm{CuO}$ nanowires/GCE recorded in $0.1 \mathrm{M}$ phosphate buffer (pH 7.4) in the absence and presence of (a) blank (b) $100 \mu \mathrm{M}$ UA (c) $100 \mu \mathrm{M}$ CA (d) $100 \mu \mathrm{M}$ AA (e) $100 \mu \mathrm{M}$ DA (f) $100 \mu \mathrm{M} \mathrm{Nacl}$ (g) $100 \mu \mathrm{M}$ glucose and (h) mixture of $100 \mu \mathrm{M}$ of each species (A) cyclic voltammetry (CV) curves and (B) DPV curves, respectively.

\subsection{Stability/Reproducibility of the $\mathrm{CuO}$ Nanowires/GCE}

Figure 12 illustrates the reproducibility and stability of the $\mathrm{CuO}$ nanowires/GCE towards $0.2 \mathrm{mM}$ DA for the estimation of the sensing performance and the stability was tested using the electrode for 50 multiple CV cycles.

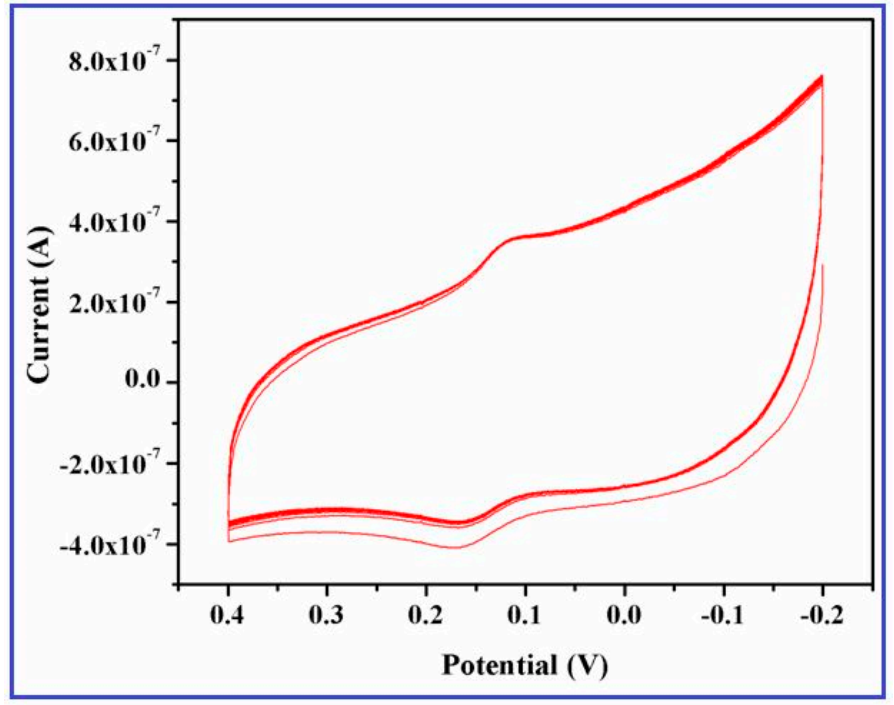

Figure 12. Fifty repeated CV scans of the $\mathrm{CuO}$ nanowires/GCE in $0.2 \mathrm{mM}$ DA at a scan rate $50 \mathrm{mV} / \mathrm{s}$.

Only a $5.8 \%$ decrease of redox peak current was observed, even after 50 cycles, indicating the good stability of the electrode. In the reproducibility tests, six independently fabricated $\mathrm{CuO}$ nanowires modified electrodes were investigated and the electrochemical performance of each modified electrode was measured in a $0.2 \mathrm{mM}$ DA solution. The estimated relative standard deviation for the oxidation of DA was calculated to be $2.36 \%$. The observed results obviously displayed the adequate reproducibility of the newly designed electrode material ( $\mathrm{CuO} /$ nanowires) toward the determination of DA.

\section{Conclusions}

We have developed an efficient electrochemical biosensor using $\mathrm{CuO}$ nanowires and tested towards the selective and sensitive determination of DA. The $\mathrm{CuO}$ nanowires, like morphology, 
were developed through a facile green synthetic protocol employing Sapindus mukorossi fruit extract as a biosurfactant. The structural, crystalline, and morphological characteristics of the $\mathrm{CuO}$ nanowires were investigated using XRD, XPS, FTIR, FE-SEM, and HR-TEM analyses. This green synthesis method is a versatile, large-scale, cost-effective, and spontaneous production method for $\mathrm{CuO}$ nanostructures for energy and biological applications. Here, the proposed $\mathrm{CuO}$-nanowire-modified sensor showed high selectivity and sensitivity, a low detection limit, and a relatively wide dynamic range, demonstrating its potential for the development of an eco-friendly platform for the detection of dopamine or related neurochemicals. Furthermore, the valid response to DA obtained in this present work indicates the promise of the $\mathrm{CuO}$ nanowires for the detection of other biological molecules, such as nucleic acids, proteins, and enzymes. This new sensor opens opportunities for the fast, simple, and selective detection of DA and it provides a promising platform for biosensor applications.

Author Contributions: All the authors were equally contributed and strong collaborative for the preparation of this manuscript. S.S. was carried out the associated experiments and wrote the manuscript under the guidance of G.V. and S.J.K. Finally, all the authors approved the final version of the manuscript.

Funding: This research was funded by the Basic Science Research Program through the National Research Foundation of Korea (NRF) funded by the Ministry of Science, ICT and Future Planning (2018R1A2B6009591).

Acknowledgments: Sasikala Sundar is thankful for providing financial support from Department of Science and Technology (DST), India DST for providing fellowship and financial support through National Postdoctoral Fellowship (N-PDF, PDF/2016/002184) scheme under the project number GAP 23/16. Sasikala Sundar and Ganesh Venkatachalam acknowledge CSIR-CECRI, Central Instrumentation Facility (CIF), Karaikudi for providing the necessary instruments for the characterization of the materials. Sasikala Sundar and Seong Jung Kwon were supported by the Basic Science Research Program through the National Research Foundation of Korea (NRF) funded by the Ministry of Science, ICT and Future Planning (2015R1A1A1A05027693, 2018R1A2B6009591). This paper was written as part of Konkuk University's research support program for its faculty on sabbatical leave in 2016.

Conflicts of Interest: The authors declare no conflict of interest.

\section{References}

1. Xu, Z.P.; Buehler, M.J. Hierarchical nanostructures are crucial to mitigate ultrasmall thermal point loads. Nano Lett. 2009, 9, 2065-2072. [CrossRef] [PubMed]

2. Paladugu, M.; Zou, J.; Guo, Y.N.; Zhang, X.; Joyce, H.J.; Gao, Q.; Tan, H.H.; Jagadish, C.; Kim, Y. Formation of hierarchical InAs nanoring/GaAs nanowire heterostructures. Angew. Chem. Int. Ed. 2009, 48, 780-783. [CrossRef] [PubMed]

3. Wang, X.; Hu, C.; Liu, H.; Du, G.; He, X.; Xi, Y. Synthesis of $\mathrm{CuO}$ nanostructures and their application for non enzymatic glucose sensing. Sens. Actuator B Chem. 2010, 144, 220-225. [CrossRef]

4. Kim, Y.S.; Hwang, I.S.; Kim, S.J.; Lee, C.Y.; Lee, J.H. CuO nanowire gas sensors for air quality control in automotive cabin. Sens. Actuator B Chem. 2008, 135, 298-303. [CrossRef]

5. Zheng, S.F.; Hu, J.S.; Zhong, L.S.; Song, W.G.; Wan, L.J.; Guo, Y.G. Introducing dual functional CNT networks into $\mathrm{CuO}$ nanomicrospheres toward superior electrode materials for lithium-ion batteries. Chem. Mater. 2008, 20, 3617-3622. [CrossRef]

6. Zhu, Y.; Yu, T.; Cheong, F.; Xu, X.; Lim, C.; Tan, V.; Thong, J.; Sow, C.H. Large-scale synthesis and field emission properties of vertically oriented $\mathrm{CuO}$ nanowire films. Nanotechnology 2005, 16, 88-92. [CrossRef]

7. Kim, J.; Park, J.; Park, K. CuO hollow nanostructures catalyze [3 + 2] cycloaddition of azides with terminal alkynes. Chem. Commun. 2010, 46, 439-441. [CrossRef]

8. Xiang, J.; Tu, J.; Zhang, L.; Zhou, Y.; Wang, X.; Shi, S. Self-assembled synthesis of hierarchical nanostructured $\mathrm{CuO}$ with various morphologies and their application as anodes for lithium ion batteries. J. Power Sources 2010, 195, 313-319. [CrossRef]

9. Hsieh, C.T.; Chen, J.M.; Lin, H.H.; Shih, H.C. Synthesis of well-ordered CuO nanofibers by a self-catalytic growth mechanism. Appl. Phys. Lett. 2003, 82, 3316-3318. [CrossRef]

10. Yu, L.; Zhang, G.; Wu, Y.; Bai, X.; Guo, D. Cupric oxide nanoflowers synthesized with a simple solution route and their field emission. J. Cryst. Growth 2008, 310, 3125-3130. [CrossRef] 
11. Zhu, J.; Bi, H.; Wang, Y.; Wang, X.; Yang, X.; Lu, L. Synthesis of flower-like CuO nanostructures via a simple hydrolysis route. Mater. Lett. 2007, 61, 5236-5238. [CrossRef]

12. Teng, F.; Yao, W.; Zheng, Y.; Ma, Y.; Teng, Y.; Xu, T.; Liang, S.; Zhu, Y. Synthesis of flower-like CuO nanostructures as a sensitive sensor for catalysis. Sens. Actuator B Chem. 2008, 134, 761-768. [CrossRef]

13. Tang, X.L.; Ling, R.; Sun, L.N.; Tian, W.G.; Cao, M.H.; Hu, C.W. A solvothermal route to $\mathrm{Cu}_{2} \mathrm{O}$ nanocubes and $\mathrm{Cu}$ nanoparticles. Chem. Res. Chin. Univ. 2006, 22, 547-551. [CrossRef]

14. Wang, H.; Xu, J.Z.; Zhu, J.J.; Chen, H.Y. Preparation of $\mathrm{CuO}$ nanoparticles by microwave irradiation. J. Cryst. Growth 2002, 244, 88-94. [CrossRef]

15. Das, S.K.; Khan, M.M.R.; Guhab, A.K.; Naskar, N. Bioinspired fabrication of silver nanoparticles on nanostructured silica: Characterization and application as a highly efficient hydrogenation catalyst. Green Chem. 2013, 15, 2548-2557. [CrossRef]

16. Merims, D.; Giladi, N. Dopamine dysregulation syndrome, addiction and behavioral changes in Parkinson's disease. Parkinsonism Relat. Disord. 2008, 4, 273-280. [CrossRef] [PubMed]

17. Snowden, M.E.; Unwin, P.R.; Macpherson, J.V. Single walled carbon nanotube channel flow electrode: Hydrodynamic voltammetry at the nanomolar level. Electrochem. Commun. 2011, 13, 186-189. [CrossRef]

18. Alizadeh, T.; Mirzagholipur, S. A Nafion-free non-enzymatic amperometric glucose sensor based on copper oxide nanoparticles-graphene nanocomposite. Sens. Actuator B-Chem. 2014, 198, 438-447. [CrossRef]

19. Yue, H.Y.; Huang, S.; Chang, J.; Heo, C.; Yao, F.; Adhikari, S.; Gunes, F.; Liu, L.C.; Lee, T.H.; Oh, E.S.; et al. $\mathrm{ZnO}$ nanowire arrays on 3D hierachical graphene foam: Biomarker detection of Parkinson's disease. ACS Nano 2014, 8, 1639-1646. [CrossRef] [PubMed]

20. Rajamani, A.R.; Kannan, R.; Krishnan, S.; Ramakrishnan, S.; Raj, S.M.; Kumaresan, D.; Kothurkar, N.; Rangarajan, M. Electrochemical Sensing of Dopamine, Uric Acid and Ascorbic Acid Using tRGO-TiO 2 Nanocomposites. J. Nanosci. Nanotechnol. 2015, 15, 5042-5047. [CrossRef] [PubMed]

21. Jiang, L.; Zhang, W. Electroanalysis of Dopamine at $\mathrm{RuO}_{2}$ Modified Vertically Aligned Carbon Nanotube Electrode. Electroanalysis 2009, 21, 1811-1815. [CrossRef]

22. Salamon, J.; Sathishkumar, Y.; Ramachandran, K.; Lee, Y.S.; Yoo, D.J.; Kim, A.R.; Kumar, G.G. One-pot synthesis of magnetite nanorods/graphene composites and its catalytic activity toward electrochemical detection of dopamine. Biosens. Bioelectron. 2015, 64, 269-276. [CrossRef] [PubMed]

23. Liu, M.; Chen, Q.; Lai, C.; Zhang, Y.; Deng, J.; Li, H.; Yao, S. A double signal amplification platform for ultrasensitive and simultaneous detection of ascorbic acid, dopamine, uric acid and acetaminophen based on a nanocomposite of ferrocene thiolate stabilized $\mathrm{Fe}_{3} \mathrm{O}_{4} @ \mathrm{Au}$ nanoparticles with graphene sheet. Biosens. Bioelectron. 2013, 48, 75-81. [CrossRef] [PubMed]

24. Xie, Y.; Yuan, J.; Ye, H.; Song, P.; Hu, S. Facile ultrasonic synthesis of graphene $/ \mathrm{SnO}_{2}$ nanocomposite and its application to the simultaneous electrochemical determination of dopamine, ascorbic acid, and uric acid. J. Electroanal. Chem. 2015, 749, 26-30. [CrossRef]

25. Anithaa, A.C.; Lavanya, N.; Asokan, K.; Sekar, C. Highly sensitive and selective serotonin sensor based on gamma ray irradiated tungsten trioxide nanoparticles. Electrochim. Acta 2015, 167, 294-302. [CrossRef]

26. Patil, S.A.; Patil, L.A.; Patil, D.R.; Jain, G.H.; Wagh, M.S. CuO-doped BSST thick film resistors for ppb level $\mathrm{H} 2 \mathrm{~S}$ gas sensing at room temperature. Sens. Actuator B Chem. 2007, 123, 246-253. [CrossRef]

27. Li, C.; Su, Y.; Zhang, S.; Lv, X.; Xia, H.; Wang, Y. An improved sensitivity non-enzymatic glucose biosensor based on a $\mathrm{Cu}_{\mathrm{x}} \mathrm{O}$ modified electrode. Biosens. Bioelectron. 2010, 26, 903-907. [CrossRef] [PubMed]

28. Sivasubramanian, R.; Biji, P. Preparation of copper (I) oxide nanohexagon decorated reduced graphene oxide nanocomposite and its application in electrochemical sensing of dopamine. Mater. Sci. Eng. B 2016, 210, 10-18. [CrossRef]

29. Steinhauer, S.; Brunet, E.; Maier, T.; Mutinati, G.C.; Kock, A.; Freudenberg, O.; Gspan, C.; Grogger, W.; Neuhold, A. Gas sensing properties of novel CuO nanowire devices. Sens. Actuator B Chem. 2013, 187, 50-57. [CrossRef]

30. Li, Y.; Zhang, Q.; Li, J. Direct electrochemistry of hemoglobin immobilized in CuO nanowire bundles. Talanta 2010, 83, 162-166. [CrossRef] [PubMed]

31. Piraman, S.; Sundar, S.; Mariappan, R.; Kim, Y.Y.; Min, K. Nanospheres and nanoleaves of $\gamma-\mathrm{Fe}_{2} \mathrm{O}_{3}$ architecturing for magnetic and biomolecule sensing applications. Sens. Actuator B Chem. 2016, 234, 386-394. [CrossRef] 
32. Wang, F.; Li, H.; Yuan, Z.; Sun, Y.; Chang, F.; Deng, H.; Xie, L.; Li, H. A highly sensitive gas sensor based on CuO nanoparticles synthetized via a sol-gel method. RSC Adv. 2016, 6, 79343-79349. [CrossRef]

33. Nasrollahzadeh, M.; Sajadi, S.; Mohammad, M. Tamarix gallica leaf extract mediated novel route for the green synthesis of $\mathrm{CuO}$ nanoparticles and their application for Narylation of nitrogen-containing heterocycles under ligand-free conditions. RSC Adv. 2015, 5, 40628-40635. [CrossRef]

34. Vijay Kumar, P.P.N.; Shameem, U.; Pratap, K.; Kalyani, R.L.; Pammi, S.V.N. Green synthesis of copper oxide nanoparticles using Aloe vera leaf extract and its antibacterial activity against fish bacterial pathogens. BioNanoScience 2015, 5, 135-139. [CrossRef]

35. Yin, M.; Wu, C.K.; Lou, Y.; Burda, C.; Koberstein, J.T.; Zhu, Y.; O’Brien, S. Copper Oxide Nanocrystals. J. Am. Chem. Soc. 2005, 127, 9506-9511. [CrossRef] [PubMed]

36. Gao, D.; Zhang, J.; Zhu, J.; Qi, J.; Zhang, Z.; Sui, W.; Shi, H.; Xue, D. Vacancy-Mediated Magnetism in Pure Copper Oxide Nanoparticles. Nanoscale Res. Lett. 2010, 5, 769-772. [CrossRef] [PubMed]

37. Nyquist, R.A.; Kagel, R.O. Infrared Spectra of Inorganic Compounds; Academic Press: New York, NY, USA; London, UK, 1997; p. 220.

38. Ethiraj, A.S.; Kang, D.J. Synthesis and characterization of $\mathrm{CuO}$ nanowires by a simple wet chemical method. Nanoscale Res. Lett. 2012, 7, 70. [CrossRef] [PubMed]

39. Halder, M.; Islam, M.D.M.; Ansari, Z.; Ahammed, S.; Sen, K.; Islam, S.K.M. Biogenic Nano-CuO-Catalyzed Facile C-N Cross-Coupling Reactions: Scope and Mechanism. ACS Sustain. Chem. Eng. 2017, 5, 648-657. [CrossRef]

40. Sadia, S.; Arifa, T.; Tayyaba, A.; Yongsheng, C. Plant Mediated Green Synthesis of CuO Nanoparticles: Comparison of Toxicity of Engineered and Plant Mediated CuO Nanoparticles towards Daphnia magna. Nanomaterials 2016, 6, 205. [CrossRef]

41. Umar, A.; Lee, J.H.; Kumar, R.; Al-Dossary, O.; Ibrahim, A.A.; Baskoutas, S. Development of highly sensitive and selective ethanol sensor based onlance-shaped $\mathrm{CuO}$ nanostructures. Mater. Des. 2016, 105, 16-24. [CrossRef]

42. Liu, Z.; Yang, Y.; Liang, J.; Hu, Z.; Li, S.; Peng, S.; Qian, Y. Synthesis of Copper Nanowires via a Complex-Surfactant-Assisted Hydrothermal Reduction Process. J. Phys. Chem. B 2003, 107, 12658-12661. [CrossRef]

43. Liu, J.; Jin, J.; Deng, Z.; Huang, S.Z.; Hu, Z.Y.; Wang, L.; Wang, C.; Chen, L.H.; Li, Y.; VanTendeloo, G.; et al. Tailoring $\mathrm{CuO}$ nanostructures for enhanced photocatalytic property. J. Colloid Interface Sci. 2012, 384, 1-9. [CrossRef] [PubMed]

44. Yang, C.; Xiao, F.; Wang, J.; Su, X. 3D flower- and 2D sheet-like CuO nanostructures: Microwave-assisted synthesis and application in gas sensors. Sens. Actuator B Chem. 2015, 207, 177-185. [CrossRef]

45. Qin, Y.; Zhang, F.; Chen, Y.; Zhou, Y.; Li, J.; Zhu, A.; Luo, Y.; Tian, Y.; Yang, J. Hierarchically Porous CuO Hollow Spheres Fabricated via a One-Pot Template-Free Method for High-Performance Gas Sensors. J. Phys. Chem. C 2012, 116, 11994-12000. [CrossRef]

46. Devaraj, M.; Saravanan, R.; Deivasigamani, R.K.; Gupta, V.K.; Gracia, F.; Jayadevan, S. Fabrication of novel shape $\mathrm{Cu}$ and $\mathrm{Cu} / \mathrm{Cu}_{2} \mathrm{O}$ nanoparticles modified electrode for the determination of dopamine and paracetamol. J. Mol. Liq. 2016, 221, 930-941. [CrossRef]

47. Pandikumar, A.; How, G.T.S.; See, T.P.; Omar, F.S.; Jayabal, S.; Kamali, S.Z.; Yusoff, N.; Jamil, A.; Ramaraj, R.; John, S.A.; et al. Graphene and its nanocomposite material based electrochemical sensor platform for dopamine. RSC Adv. 2014, 4, 63296-63323. [CrossRef]

48. Felix, S.; Kollu, P.; Raghupathy, B.P.C.; Jeong, S.K.; Grace, A.N. Electrocatalytic oxidation of carbohydrates and dopamine in alkaline and neutral medium using $\mathrm{CuO}$ nanoplatelets. J. Electroanal. Chem. 2015, 739, 1-9. [CrossRef]

49. Reitz, E.; Jia, W.; Gentile, M.; Wang, Y.; Lei, Y. CuO Nanospheres Based Nonenzymatic Glucose Sensor. Electroanalysis 2008, 20, 2482-2486. [CrossRef]

50. Li, J.; Yang, Z.; Yang, Y.; Li, S.; Yu, Q.; Xu, X.; Hu, X. Graphene-Au nanoparticles nanocomposite film for selective electrochemical determination of dopamine. Anal. Methods 2012, 4, 1725-1728. [CrossRef]

51. Kim, Y.R.; Bong, S.; Kang, Y.J.; Yang, Y.; Mahajan, R.K.; Kim, J.S.; Kim, H. Electrochemical detection of dopamine in the presence of ascorbic acid using graphene modified electrodes. Biosens. Bioelectron. 2010, 25, 2366-2369. [CrossRef] [PubMed] 
52. Ma, Y.; Zhao, M.; Cai, B.; Wang, W.; Ye, Z.; Huang, J. 3D graphene network@WO nanowire composites: A multifunctional colorimetric and electrochemical biosensing platform. Chem. Commun. 2014, 50, 11135-11138. [CrossRef] [PubMed]

53. Aparna, T.K.; Sivasubramanian, R.; Dar, A.H. One-pot synthesis of Au Cu2O/rGO nanocomposite based electrochemical sensor for selective and simultaneous detection of dopamine and uric acid. J. Alloys Compd. 2018, 741, 1130-1141. [CrossRef]

54. Gao, F.; Cai, X.; Wang, X.; Gao, C.; Liu, S.; Gao, F.; Wang, Q. Highly sensitive and selective detection of dopamine in the presence of ascorbic acid at graphene oxide modified electrode. Sens. Actuator B Chem. 2013, 186, 380-387. [CrossRef]

55. Wang, C.; Du, J.; Wang, H.; Zou, C.E.; Jiang, F.; Yang, P.; Du, Y. A facile electrochemical sensor based on reduced graphene oxide and Au nanoplates modified glassy carbon electrode for simultaneous detection of ascorbic acid, dopamine and uric acid. Sens. Actuator B Chem. 2014, 204, 302-309. [CrossRef]

56. Liu, B.; Ouyang, X.; Ding, Y.; Luo, L.; Xu, D.; Ning, Y. Electrochemical preparation of nickel and copper oxides-decorated graphene composite for simultaneous determination of dopamine, acetaminophen and tryptophan. Talanta 2016, 146, 114-121. [CrossRef] [PubMed]

57. Palanisamy, S.; Ku, S.; Chen, S.M. Dopamine sensor based on a glassy carbon electrode modified with a reduced graphene oxide and palladium nanoparticles composite. Microchim. Acta 2013, 180, 1037-1042. [CrossRef]

58. Reddy, S.; Swamya, B.E.K.; Jayadevappa, H. CuO nanoparticle sensor for the electrochemical determination of dopamine. Electrochim. Acta 2012, 61, 78-86. [CrossRef]

59. Kaur, B.; Pandiyan, T.; Satpati, B.; Srivastava, R. Simultaneous and sensitive determination of ascorbic acid, dopamine, uric acid, and tryptophan with silver nanoparticles-decorated reduced graphene oxide modified electrode. Colloids Surf. B 2013, 111, 97-106. [CrossRef] [PubMed]

60. Yang, S.; Li, G.; Yin, Y.; Yang, R.; Li, J.; Qu, L. Nano-sized copper oxide/multi-wall carbon nanotube/Nafion modified electrode for sensitive detection of dopamine. J. Electroanal. Chem. 2013, 703, 45-51. [CrossRef]

61. Aravind, S.S.J.; Ramaprabhu, S. Dopamine biosensor with metal oxide nanoparticles decorated multi-walled carbon nanotubes. Nanosci. Methods 2012, 1, 102-114. [CrossRef]

62. Krishnamoorthy, K.; Sudh, V.; Kumar, S.M.S.; Thangamuthu, R. Simultaneous determination of dopamine and uric acid using copper oxide nano-rice modified electrode. J. Alloys Compd. 2018, 748, 338-347. [CrossRef]

63. Suna, W.; Wang, X.; Wang, Y.; Ju, X.; Xu, L.; Li, G.; Suna, Z. Application of graphene-SnO 2 nanocomposite modified electrode for the sensitive electrochemical detection of dopamine. Electrochim. Acta 2013, 87, 317-322. [CrossRef]

64. Sheng, Z.H.; Zheng, X.Q.; Xu, J.Y.; Bao, W.J.; Wang, F.B.; Xia, X.H. Electrochemical sensor based on nitrogen doped graphene: Simultaneous determination of ascorbic acid, dopamine and uric acid. Biosens. Bioelectron. 2012, 34, 125-131. [CrossRef] [PubMed]

65. Wang, Y.; Li, Y.; Tang, L.; Lu, J.; Li, J. Application of graphene-modified electrode for selective detection of dopamine. Electrochem. Commun. 2009, 11, 889-892. [CrossRef]

(C) 2018 by the authors. Licensee MDPI, Basel, Switzerland. This article is an open access article distributed under the terms and conditions of the Creative Commons Attribution (CC BY) license (http:// creativecommons.org/licenses/by/4.0/). 